\title{
O testemunho de viagem: entre referências desgastadas e influência do mercado turístico
}

\author{
Travel's Testimony: Between wasted references and tourism \\ trade's influency
}

\section{Le témoinage de voyage: Entre anciennes références et influence du marché du tourisme}

Júlia Fonseca de Castro

Universidade Federal de Minas Gerais

juliafcastro@gmail.com

\begin{abstract}
Resumo
As narrativas de viagem convidam à leitura por estarem vinculadas a diversas áreas do conhecimento e da sensibilidade, suscitando reflexões, dentre elas, sobre a formação e a propagação de discursos de/sobre viagem. Dentro do universo da literatura de viagem, propõe-se uma leitura transversal de textos que são marcados pela valorização do testemunho. Prioritariamente entendido como prova e fragmento da verdade, o testemunho do típico narrador-viajante adquire, ao longo do tempo, um caráter de encenação. Da mesma forma, a ênfase na viagem como modo de testemunhar os lugares assume a forma de práticas superficializadas. Anunciadas como bens de consumo, as viagens são comercializadas em pacotes "estampados" com imagens-clichê, produzidas para estimular a contemplação fácil e o registro rápido durante percursos padronizados. A forte influência do mercado turístico na conformação da cultura das viagens estimula uma renovação nas tradicionais identidades do viajante, que tendem a ser inspiradas na ideia do viajante-testemunha. As anotações de viagem de Alain de Botton e Claude Lévi-Strauss auxiliam a reflexão.
\end{abstract}

Palavras-chave: viagem, literatura de viagem, mercado turístico, identidade do viajante.

\footnotetext{
Abstract

Travel narratives are inviting for the reading because they are linked to several areas of knowledge and sensibility, and bring up reflections, among them, about the structuring and propagation of travel discourse. Inside the universe of travel literature, we propose a transversal reading of the texts that are distinguished by valorization of the testimony. Previously understood as proof and fragment of the
} 
truth, the typical traveler-narrator testimony acquires, in time, an ethos of playacting. In the same way, the emphasis on traveling as a way to witness places takes the shape of superficialized practices. Portrayed as consumer goods, travels are sold as "colorful" packages with cliché images that boost easy admiration and quick registering throughout standard routes. The tourism trade's strong influence in structuring travel culture boosts a renewal of the traditional traveler identities, usually inspired by the notion of travelers as witnesses. The travel notes from Alain Botton and Claude Lévi-Strauss are helpful on this reflection.

Keywords: Travel, travel's literature, tourism trade, traveler identity.

\section{Résumé}

Les récits de voyage nous invitent à la lecture, en raison de leur liason avec des différends domaines de la connaissance, de la sensibilité et la propagation du discours à propos des voyages. Dans l'univers de la littérature de Voyage, nous proposons une lecture croisée des textes qui mettent en valeur le témoignage du voyageur. Le témoignage type de ce narrateur-voyageur est entendu, la plupart du temps, comme une preuve et/ou morceau de vérité. Alors, au long du temps, il devient une mise en scène du voyage. De même, l'accent mis sur le voyage comme moyen d'appréhender les lieux engendre des habitudes de voyages superficiels. Les voyages, annoncées comme des biens de consommation, sont vendus en "packs " par des images clichés produites afin de stimuler la contemplation et/ou l'inscription facile et rapide dans des voies standardisées. La forte influence du marché du tourisme dans l'élaboration de la culture du voyage stimule un renouvellement des identités traditionnelles du voyageur qui ont tendance à être inspiré par ce narrateurvoyageur. Les notes de voyage de Alain de Botton et Claude Lévi- Strauss nous aideront durant notre réflexion.

Mots-clés: Voyage, littérature de voyage, marché du tourisme, identité du voyageur.

\section{Apresentação}

O presente artigo é resultante de uma pesquisa de natureza teórico-conceitual, sobre o tema das viagens, que foi defendida no Programa de Pós-graduação em Geografia da Universidade Federal de Minas Gerais, cujo título é Uma leitura das viagens contemporâneas: a questão do testemunho nas narrativas de viagem (CASTRO, 2013). Neste artigo, interpreta-se a ideia contemporânea de viagem sustentada pelo mercado/ indústria do turismo. O artigo expõe os caminhos reflexivos percorridos na referida pesquisa e as discussões travadas a partir do objetivo de pensar o conceito de viagem que é hegemônico em nossos dias e sua conformação em um discurso geral a que chamamos de viagem de testemunho.

Tal discurso, em nosso entendimento, foi disseminado a partir de princípios da modernidade, com a propagação das viagens e, consequentemente, das narrativas e relatos que, ao terem o alcance ampliado em função do número alargado de publicações e leitores, difundiram a ideia de que viajar é testemunhar. Sugere-se que esse discurso define e valoriza a atividade de viajar como modalidade de deslocamento espacial direcionada à produção de testemunhos, com a finalidade de confirmar e de atestar - viajar se torna atividade de ver/observar para, então, relatar/narrar/testemunhar o visto; confirmar/ 
atestar. Com raízes no gênero literário de viagem - instância de criação e difusão de imaginário cultural -, o discurso da viagem de testemunho teria sido deslocado e hoje seria produzido intensamente pela publicidade do turismo.

Este artigo convida a pensar o discurso publicitário do mercado do turismo, bem como as práticas do viajante contemporâneo voltadas ao consumo dos lugares.

\section{A exclusão teórica de mobilidades e práticas de viagem e a necessidade de leituras abrangentes}

É importante pensar que a viagem, quando tratada exclusivamente como um tipo de deslocamento espacial, aquele relacionado ao sistema de turismo nacional e internacional, é compreendida de modo restrito, e esse é um problema no que concerne às abordagens teóricas que se centram no tema turismo. Há, na interpretação da viagem prioritariamente a partir dos aspectos comerciais relacionados ao turismo, um foco excessivo nos viajantes que movimentam o mercado, em detrimento de uma série de outras práticas importantes e grupos de viajantes desenquadrados do papel de consumidores-turistas - sejam eles desvinculados de tal mercado por opção ou por ausência de condições para tanto.

Em termos conceituais, a discussão sobre o tema viagem a partir da teoria do turismo demanda reflexões cuidadosas. Cabe ressaltar a teoria que trata a atividade turística como um tipo de indústria. A teoria do sistema turístico, paradigma dominante do campo, como apontam Guilherme Palhares e Alexandre Panosso Netto (2008), foi criada a partir do reconhecimento do turismo como força econômica e da eleição de sua indústria como objeto principal dos estudos sobre o tema. Uma vez que a ideia do turismo-indústria se tornou predominante, a viagem passou a ser trabalhada de acordo com a importância que representa para a cadeia produtiva do turismo - as primeiras definições e conceituações sobre o tema expressam tal conotação dada à viagem, como destaca Margarita Barreto (1995) -, de modo que as abordagens sobre sua dimensão histórica e social acabaram por se tornar secundárias. Ao se priorizar o entendimento da viagem como bem de consumo, se exclui a diversidade de significados vinculados às práticas dos viajantes produzidos ao longo do tempo. Excluem-se, com essa abordagem teórica, sujeitos e práticas que deveriam ser considerados nos estudos que se propõem a compreender a natureza da viagem e suas características contemporâneas.

Como pensar o turismo e dimensionar as viagens contemporâneas sem reduzilas ao suposto papel de engrenagem a ser aperfeiçoada no sentido de apurar a dimensão lucrativa? É necessário, fundamentalmente, recusar a caracterização das viagens como mobilidade espacial só relacionada ao sistema turístico. Também é preciso refletir sobre o conceito de viagem. Esse se desdobra entre as mais diversas áreas do conhecimento e pode ser considerado um tema fronteiriço. $\mathrm{O}$ aludido sentido de fronteira é o pensado por Cássio Hissa (2006), com relação à dinâmica da produção do conhecimento que, segmentada entre a ciência, as artes, a filosofia e, também, os saberes populares, demanda hoje nova "interpenetração de saberes" (HISSA, 2006, p. 307). Seria importante tratar 
o tema das viagens de modo transdisciplinar, a fim de contemplar a diversidade de significados, a construção histórica, as dimensões contemporâneas que abrangem aspectos culturais, demográficos, econômicos e geográficos, dentre outros que devem ser abordados de maneira integrada. Somente assim é possível evitar um pensamento fragmentado que acabe por reduzir a complexidade do tema e desconsiderar a polissemia própria à ideia viagem.

No que diz respeito à geografia e à relação disciplinar estabelecida com o tema das viagens, observam-se dois importantes aspectos. Primeiramente, a tendência em compreender o viés socioespacial da viagem a partir de estudos centrados nos grandes fluxos espaciais produz os mesmos problemas mencionados anteriormente: a exclusão de práticas e significados dos deslocamentos que não respondam aos pressupostos do sistema global das viagens. Superar essa visão segregadora é fundamental.

Outro aspecto importante da abordagem geográfica direcionada ao assunto se relaciona ao estudo das narrativas de viagem que contribuíram para diversas disciplinas científicas, inclusive para o processo de reunião e sistematização dos relatos de viajantes no âmbito da história do pensamento geográfico. Acreditamos ser importante evitar o tratamento da literatura de viagem como fonte sem a devida crítica acerca de bases epistemológicas e vínculos institucionais ou sem considerar o tratamento comumente dado aos relatos pelo mercado editorial. Além disso, interpretações que se voltem somente à finalidade de reconstruir algum tipo de gênese sobre questões atuais ou categorias disciplinares, buscando seus aspectos históricos, tendem a resultar em leituras fragmentadas, que costumam desconsiderar totalmente os aspectos relacionados à produção e à recepção dos textos. Esses são riscos a serem evitados no que diz respeito ao enfoque dado pela geografia, e outras disciplinas, aos relatos de viagem.

Nesse sentido, consideramos de interesse dos estudos socioespaciais e geográficos a exploração dos relatos de viagem com o objetivo de discutir de modo mais abrangente o conceito de viagem e a atividade dos viajantes, sem restringir-se à sua dimensão literária/textual/documental.

O objetivo principal do artigo é refletir sobre o discurso de viagem produzido pelo mercado turístico, buscando investigar seus pressupostos, definições e características por meio da literatura de viagem. Objetiva-se pensar a relação entre o consumo e as práticas contemporâneas dos viajantes, discutindo a configuração da viagem como um testemunho em narrativas e relatos.

A metodologia utilizada apresenta como premissa a ideia de que a literatura não se encerra em si mesma e que especialmente a narrativa seja constituída por uma rede complexa de conexões entre a experiência prática dos sujeitos do mundo e um uso especial da linguagem, tal como propõe Paul Ricoeur (1994). Sendo assim, para pensar a relação entre literatura e experiência de viagem, consideramos o diálogo entre autores e leitores que ressignificam suas práticas por meio dos relatos e narrativas, não nos prendendo aos aspectos internos dos textos, mas buscando a relação entre relato e experiência. 
Propomos a análise de textos literários e textos teóricos e científicos, deslocando-os para um mesmo nível, que permita o diálogo e a complementação entre os discursos científico e literário. Parte-se do texto, pensando-o como objeto dotado de significação e, simultaneamente, produto de criação ideológica, ou seja, resultante de contextos históricos, sociais e culturais. O interior do texto é dialógico, pois se configura como espaço de diálogo entre os interlocutores e entre outros textos (BRAIT, 1997). A abordagem dialógica é aqui solicitada de forma a auxiliar na exposição da complexidade que envolve o tema das viagens, tendo a linguagem como fio condutor.

Optamos, portanto, por analisar textos teóricos que trabalhem o gênero literatura de viagem e, também, textos de autores-viajantes que apresentem questões pertinentes ao assunto discutido. Para tratar o teor testemunhal da literatura de viagem, realizaremos uma leitura transversal do gênero, a fim de destacar algumas características. Em seguida, buscaremos interpretar as anotações de/sobre viagem dos seguintes livros: Tristes trópicos, de Lévi-Strauss, e $A$ arte de viajar, de Alain de Botton. Enquanto LéviStrauss realiza uma leitura crítica dos modismos e da encenação nas quais a atividade dos viajantes exploradores acabou envolvida, ainda no século XX, Alain de Botton nos auxilia a refletir sobre as relações entre viagem e consumo e os impactos dessa relação na própria constituição da experiência do viajante.

\section{O testemunho de viagem: a literatura e as práticas contemporâneas dos viajantes}

As viagens, como qualquer outra prática cultural antiga, passam por ressignificações à medida que cada período e cada contexto lhes concedem um conjunto de parâmetros, orientações e finalidades diversas. São readequadas, assim como são atualizados os discursos que fundamentam as práticas dos viajantes. Quando pensamos em discursos de viagem/sobre viagem, estamos nos referindo às respostas dadas a perguntas fundamentais, como, por exemplo: o que é viajar? O que é viajar hoje? Como aprendemos sobre viagens e que tipo de comportamento, conquista ou modo de vida são representados pela atividade dos viajantes? Qual a importância que atribuímos às viagens?

É possível afirmar que, antes mesmo dos avanços nos meios de comunicação e transporte, as viagens ganharam um grande impulso a partir de acontecimentos que se tornaram referências históricas e que geraram a construção de um arsenal de representações de encontros, situações e eventos em imagens, ilustrações, textos, cartas, diários, livros, dentre outros tipos de registro. A publicação das histórias daqueles que "descobriram" civilizações, resquícios delas e tesouros, viveram situações inusitadas, participaram de episódios históricos, bem como daqueles que elaboraram minuciosos relatórios e cartas inventariando as terras então "recém-descobertas", foi crucial para a difusão de viagens e personagens famosos e para a propagação de um conceito geral sobre "o que é viajar" e sobre "qual é o papel do viajante".

A literatura de viagem é uma importante referência para os viajantes, que, ao criarem suas próprias identidades, inspiram-se em personagens tornados mais ou menos 
famosos por terem vivenciado situações que se tornaram típicas. É relevante pensar a importância da literatura de viagem não apenas como fonte de informação ou a partir de ser caráter histórico-documental. Sobre o trabalho acadêmico envolvido na literatura de viagem, Mary Louise Pratt (1999) afirma que:

Ele é frequentemente laudatório, recapitulando as explorações de intrépidos excêntricos ou cientistas dedicados. Em outras instâncias, é um documentário, debruçando-se sobre os relatos de viagem como fontes de informação a respeito dos lugares, povos e épocas que discute (...). (PRATT, 1999, p. 37).

Nesse sentido, são necessárias leituras mais abrangentes com relação à dimensão que o gênero adquiriu ao longo do tempo. Fernando Cristovão (1999) indica a existência de uma ligação entre a decadência da literatura de viagem ${ }^{1}$ - que movimentou um importante mercado editorial entre os séculos XVI e XIX - e a popularização do turismo. Essa possível relação, ainda que pareça simplificar uma série de aspectos históricos que alicerçaram a expansão dos modos de vida capitalistas (e do surgimento do turismo, por consequência), aponta o papel fundamental exercido pela literatura na criação de uma memória cultural das viagens. Sugere, também, que tal memória cultural nunca foi estanque ou destinada a conservar informações e/ou documentos históricos, mas, dinâmica, criou e difundiu discursos sobre o ato de viajar e difundiu identidades de viajantes.

Navegadores, missionários, aventureiros, cientistas naturalistas, cartógrafos, antropólogos, jornalistas, cronistas, dentre outras variações na identidade dos viajantes, podem ser encontrados na literatura de viagem, mas é necessário um foco definido para lidar com "terreno" tão amplo quanto o do referido gênero, que é feito de modalidades textuais diversas (crônicas, romances, cartas, dentre outros), com variadas temáticas, destinatários e, muitas vezes, financiadores diversos. Com o objetivo de refletir sobre os tipos de viajante e sobre os discursos que fundamentam e justificam suas práticas, buscamos abarcar um aspecto elementar próprio do gênero: o fato de os fragmentos de saber, conhecimento, curiosidades e informações estarem reunidos nas palavras daquele que os apresenta, como se os oferecesse em "primeira mão" ao leitor.

Narrando em primeira pessoa, o típico narrador de viagem era, de alguma maneira, autorizado a relatar aspectos autênticos ou exclusivos, reconhecendo-se como uma espécie de mediador ou testemunha. Em tom de exclusividade ou novidade, os narradores-viajantes inventariavam, reuniam e apresentavam achados e situaçõeslimite, comportando-se tal como uma testemunha, ainda que assumindo a identidade de cientista, repórter, aventureiro, dentre outras. A viagem se tornava, portanto, um motivo para a escrita e a produção de todo tipo de relato, e o narrador-típico se voltava cada vez mais ao papel de testemunha, de modo que suas histórias fossem recebidas como o mais autêntico possível.

1. A literatura de viagem é considerada um gênero ou subgênero literário, que apresenta características próprias: "semiológicas, históricas, de edição e de recepção" (CRISTOVÃO, 1999, p. 16). 
A condição de testemunha, dos narradores da literatura de viagem, nos estimula a fazer uma comparação com o comportamento comum dos viajantes contemporâneos em massificadas práticas de viagem. Afinal, tal como testemunhas interessadas em comprovar a viagem, muitos viajam engajando-se em produzir grande número de fotografias nas quais, não raramente, aparecem ao lado do monumento famoso, na frente da paisagem consagrada. O clichê da fotografia expressa essa necessidade de fornecer algum tipo de prova de que efetivamente a viagem ocorreu:

A fotografia desenvolve-se na esteira de uma das atividades modernas mais típicas: o turismo. Pela primeira vez na história, pessoas viajam regularmente, em grande número, para fora de seu ambiente habitual, durante breves períodos. Parece decididamente anormal viajar por prazer sem levar uma câmera. As fotos oferecerão provas incontestáveis de que a viagem se realizou, de que a programação foi cumprida, de que houve diversão. As fotos documentam sequências de consenso realizadas longe dos olhos da família, dos amigos, dos vizinhos. (SONTAG, 2004, p. 19).

Esses viajantes-testemunha contemporâneos, orientados pela pressa na visitação do maior número de lugares em menor período de tempo, em itinerários padronizados e organizados conforme uma hierarquia fortemente baseada na visibilidade, estariam fixados na necessidade de fazer da viagem um meio de acrescentar algo à sua própria imagem. A viagem se torna um rito social, cuja comprovação alimenta o status social dos sujeitos.

Ao apontarmos a identificação dos viajantes contemporâneos como testemunhas, chegamos à conclusão de que o testemunho de viagem é marcado por um tipo de degradação da ideia de contemplação do mundo para encaminhar o conhecimento que é construído acerca dele. $\mathrm{O}$ testemunho de viagem está mais associado à composição do status social do viajante que à construção de conhecimento ou à interpretação dos lugares visitados. Nesse sentido, acreditamos que é importante refletir sobre o viajante-testemunha como uma referência em crise e, principalmente, meditar sobre a transformação da experiência de viagem em prática de produção de testemunhos.

\section{Ver com os próprios olhos, narrar com as próprias mãos}

$\mathrm{Na}$ literatura de viagem, é recorrente a presença de frases que buscam afirmar a legitimidade do que está sendo narrado, cujas origens podem ser associadas ao Livro das maravilhas, de Marco Polo, no qual havia forte preocupação por parte do narrador em assinalar a legitimidade do que era contado. Logo na introdução das histórias do jovem veneziano que havia percorrido os reinos da Ásia, entre os quais, a corte do imperador mongol Kublai Khan, no final do século XIII², encontramos essa preocupação:

Encontrareis aqui também outras coisas que, embora ele [Marco Polo] não tenha visto, ouviu dizer de pessoas dignas de fé; mas, atenção, porque as coisas

2. A obra de Marco Polo foi escrita por volta de 1300, mas traduzida para diversas línguas a partir do século XV. 
vistas ele dirá que viu, e as ouvidas dirá que ouviu, de forma que o nosso livro seja verdadeiro, sem nenhuma mentira. (POLO, 2005, p. 21).

Mesmo contendo um relato abundante em maravilhas, como homens com rabo, galinhas com pelo de gato, gigantes, dentre outros elementos fabulosos, o livro, que se tornou um clássico sobre o imaginário medieval, insiste na distinção entre verdade e mentira. Essa necessidade em localizar o relato na esfera da "realidade" acabou por se tornar uma máxima na literatura de viagem, atestada pela presença frequente de frases que também inauguram o livro de Marco Polo, tais como "eu vi com os próprios olhos" e "escutei com os próprios ouvidos".

A alusão ao testemunho pessoal, explícita nas marcas de enunciação que se transformaram em um clichê do gênero, é uma estratégia voltada a ganhar a adesão do leitor, funcionando como solução retórica que confere autoridade ao narrador. Esse clichê do gênero remete à idade média e às aventuras de Marco Polo, no período de expansão das viagens; na época do descobrimento, tornou-se mais presente ainda. Naquele contexto, "ver com os próprios olhos" era mais que uma motivação curiosa, mas um tipo de certificado por meio da escrita, baseado em dados precisos que visavam documentar rituais de posse das novas terras e indicar novas possibilidades de enriquecimento. A literatura de viagem ganha corpo principalmente com a invenção da imprensa e a divulgação, a produção e a distribuição de um largo número de narrativas ${ }^{3}$. A atuação dos editores foi fundamental para a adaptação e a incorporação de todo tipo de escritos cuja motivação é a viagem: documentos, cartas, diários, narrativas, relatórios, diários de bordo, crônicas, cadernos de anotações pessoais, guias turísticos, monografias etnográficas, romances e outros (MATOS, 2007).

Os relatos que eram então incorporados às publicações de viagem tratavamse, muitas vezes, de documentos dirigidos às instituições financiadoras das viagens e acabavam por ser adaptados e publicados para um grupo de leitores mais amplo. Nos relatos que remontam à época do descobrimento, o narrador-viajante buscava evidências palpáveis - principalmente, a disponibilidade de ouro ou outro metal precioso $^{4}$. Conforme o conhecimento sobre os continentes e regiões até então remotos era ampliado, as viagens deixavam de representar exatamente a ousadia que resultava em descobertas inéditas - atividade reservada aos corajosos exploradores e aventureiros. E passavam a atrair interesses diversificados, que resultaram em relatos elaborados por cientistas, comerciantes, jornalistas, cronistas, diplomatas, dentre outros. Já na época do Renascimento ou do Século das Luzes, os relatos cumpriam uma função ilustrativa, concebidos como veículos de informações e conhecimentos diversos.

O conjunto de textos que então era incorporado pelas editoras se tornava cada vez mais diversificado. Desde relatos com publicação de antemão encomendada, cartas e inventários com destinatários diversos até documentos voltados para as instituições

3. O público leitor inicial da literatura de viagem seria, de forma geral, europeu. No Brasil, a literatura de viagem foi também muito popular, principalmente entre os séculos XVII e XIX (SUSSEKIND, 1990).

4. Mas também se guiava pela possibilidade de "confirmar" o imaginário medieval, suas monstruosidades e prodígios, como "dragões, centauros, sereias, lobisomens, animais fabulosos". (BENASSAR, 2000, p. 92). 
científicas, que passavam a financiar as viagens. A viagem representava a possibilidade de exercício da razão, um meio de acesso a outras culturas, prática da observação e descrição de ambientes que não eram familiares aos naturalistas e etnógrafos - os principais cientistas viajantes da época ${ }^{5}$.

Diários de viagem, etnografias, catálogos de espécies de fauna, flora: publicações em que o narrador buscava a escrita objetiva, neutra, pormenorizada em datas, descrições do clima e demais detalhes que marcavam o método ensaiado in loco. O teor testemunhal das narrativas se convertia no uso de outros recursos diretamente relacionados a um estilo de escrita caracterizado como científico. Não apenas "ver com os próprios olhos", mas proporcionar ao leitor uma descrição detalhada do observado e testado durante a viagem.

A escrita da viagem se tornou uma necessidade no sentido da documentação e da organização de dados e memórias, também passou a exercer um papel social importante. À medida que ganhava espaço também nos folhetins, periódicos e jornais, o texto de viagem difundia informações e conhecimentos ${ }^{6}$. Nesse sentido, o narrador assumia outro papel: não exatamente de viajante corajoso, que apresenta, por meio de seu relato, uma fração de territórios longínquos, mas de um instrutor que propiciava aos leitores acessar informações históricas, geográficas, itinerários e mapas. Homens comuns, que não fossem aventureiros, cientistas e que não fizessem parte de uma reduzida aristocracia que possuía recursos financeiros para deslocar-se, por meio dos relatos, poderiam, de alguma maneira, também viajar por terras exóticas e longínquas.

A literatura de viagem surgia, portanto, tributária do que poderíamos chamar de teor testemunhal. O típico narrador-viajante se reconhecia e se afirmava como portador de uma realidade pouco conhecida, estranha, exótica. Além da exclusividade, contava com algo que favorecia a recepção de seu relato: o fato de ser um sobrevivente, um herói ou apenas alguém capaz de realizar uma atividade que, em outros tempos, era extremamente arriscada e perigosa. Com relação à recepção de tais relatos, é importante destacar que um testemunho tende a causar a solidariedade instantânea do leitor, pois atua "mobilizando a empatia e desarmando a incredulidade" (SELIGMANN-SILVA, 2003, p. 379).

Aos poucos, a suposta autenticidade dos relatos de viagem foi perdendo a força durante o processo de formação das colônias, de crescimento da produção industrial e de desenvolvimento dos meios de transporte e comunicação. Embora o caráter de autenticidade tenha sido perdido ou relativizado com o tempo e as narrativas tenham adquirido certo tom nostálgico, a literatura de viagem ajudou a difundir o papel de testemunha nas variadas identidades dos viajantes: aventureiros, exploradores e cientistas,

5. Após a abertura do Brasil aos estrangeiros, em 1808, os relatos resultantes de grandes expedições oficiais pelo território brasileiro destacaram viajantes como Debret, Saint Hilaire, Spix e Martius, Rugendas, Denis, Jenkins e Jonh Luccok (SUSSEKIND, 1990).

6. Durante esse longo período, a literatura de viagem incorporou um grande número de tradições culturais, como as da historiografia, da astronomia, da antropologia, da cartografia, da arquitetura, dentre outras (CRISTOVÃO, 1999). 
repórteres e cronistas. Um papel de referência para os viajantes, que deveriam orientarse pela possibilidade de fazer de sua própria viagem um meio de produzir testemunhos pessoais dos lugares visitados.

À medida que consideramos a noção de testemunho como traço fundamental de um discurso sobre as viagens contemporâneas, entendemos ser necessário encaminhar uma crítica. Em princípio, não seria questionável a ideia conceitual de testemunha, fixada em confirmar e transmitir? Principalmente no que se refere à caracterização do testemunho, muitas vezes tomado como essencial ou como formador da sua substância: portador da verdade e capaz de autenticar a veracidade contida no mundo visto? Esse mundo visto não existiria, justamente, em razão da existência do sujeito que o vê, e a visão, em tais circunstâncias, não deveria ser considerada a partir do caráter interpretativo ou representativo?

As estratégias de enunciação da literatura de viagem voltadas à persuasão ou à adesão do leitor, explícitas pela máxima do "ver com os próprios olhos", fundamentadas na noção de verdade e, portanto, autenticidade e legitimidade, precisam ser consideradas como interpretação possível do viajante-narrador. A palavra dele que se fez de relato é sempre uma possível leitura do mundo visto e, certamente, de modo parcial e de determinado ponto de vista, diante das relativas impossibilidades referentes à literalidade e frente às indesejáveis reproduções ingênuas. Assim como não se pode esperar - e muito menos exigir - a literalidade das palavras do narrador que se comporta tal como uma testemunha, é necessária uma leitura crítica das práticas de viagem que parecem inspiradas na concepção de viagem como meio de testemunhar.

O testemunho seria um traço muito elementar que, a nosso ver, pode ser interpretado como componente de um discurso geral que define o ato de viajar como mobilidade espacial voltada para a representação pessoal dos lugares. Discurso que é apropriado e disseminado hoje com mais intensidade por um mercado especializado: mídia, agências e operadoras de viagem, guias turísticos e demais instrumentos que divulgam e promovem a viagem como um tipo de consumo dos lugares, paisagens e culturas. Indagamo-nos se a obsessão por atestar não acaba comprometendo, limitando ou reduzindo a própria capacidade de experimentação envolvida na viagem. Quando a viagem faz parte de um rito social em que o mais importante é certificar o vivido por meio de fotografias ou souvenirs, o ato de experimentar parece reduzido aos prazeres da gastronomia local, às compras nos mercados típicos, ao conforto do hotel, mas, contraditoriamente, não contempla a disponibilidade do sujeito em se afetar intimamente, em se permitir se deslocar para além do espaço familiar e conhecido.

No processo de constituição de um testemunho de viagem, algo parece ter sido interrompido, conforme o ato de testemunhar, marcado pelas ideias de prova e comprovação, tende a ser marcado por certa banalidade. Tal como interpretou LéviStrauss (1996), o testemunho de viagem acabou se transformando em uma fabricação de efeito. 


\section{Transformações no testemunho de viagem}

Há pouco mais de meio século, Lévi-Strauss escrevia Tristes trópicos, livro sobre suas viagens ao Brasil e pelo interior do país, ambiguamente iniciado com uma frase que se tornou famosa: "Odeio as viagens e os exploradores". Em seu relato, o autor é inevitavelmente levado a dialogar com a literatura de viagem, mas o diálogo soa mais como advertência.

Atualmente ser explorador transformou-se num ofício: ofício que consiste não, como se poderia crer, em descobrir ao termo de anos estudiosos, alguns fatos que permaneceram desconhecidos, mas percorrer um número elevado de quilômetros e em reunir projeções fixas ou animadas, de preferência coloridas, graças às quais encher-se-á uma sala, durante muitos dias, com uma multidão de auditores para quem a insipidez e as banalidades parecerão miraculosamente transmudadas em revelações pelo único motivo do seu autor, em lugar de compilá-las num gabinete, tê-las santificado por um percurso de vinte mil quilômetros. (LÉVI-STRAUSS, 1996, p. 35).

Lévi-Strauss reconhece uma mudança na viagem de descoberta e, por consequência, no papel do viajante-explorador. Em pleno século $\mathrm{XX}$, as viagens e os (supostos) exploradores se envolvem no que o autor entende como modismo, uma encenação banal. O quadro descrito por Lévi-Strauss - sala cheia de ingênuos auditores admirados com as projeções exibidas por viajantes que, por sua vez, parecem ignorar o valor de seus testemunhos- nos faz pensar em vários aspectos relacionados às mudanças pelas quais passaram as viagens. Em primeiro lugar, pensamos no ideal de conquista, aventura e exploração envolvido nas viagens do descobrimento. Em segundo lugar, pensamos na transformação do mundo, no desenvolvimento dos meios de transporte e comunicação. E, em último lugar, no papel estereotipado que as viagens, como forma de produção de testemunhos, acabam por assumir.

Ao pensar sobre as reflexões de Tristes trópicos, a partir dos significados associados ao termo testemunho, lembramo-nos das colocações de Silviano Santiago (1989), para quem os exploradores modernos não mais precisam enfrentar os mares bravios, pois, com “[...] eficientes e potentes máquinas aéreas e delicados e sensíveis filmes, conseguem um mapeamento superior ao feito pelo antigo explorador em terra firme, e mais sofisticado" (SANTIAGO, 1989, p. 199). Não mais um meio de acesso ao desconhecido, a viagem de exploração se transforma, como interpreta Lévi-Strauss, em uma atividade de coleção de exemplares e amostras valorizadas não exatamente pelo que poderiam representar, mas pelo fato de terem sido coletadas a distância. Está aí um aspecto importante relacionado ao reposicionamento do tradicional narrador-viajante.

De atividade arriscada, extremamente custosa e imprevisível, a viagem se torna prática mais acessível. E, dessa maneira, o viajante não mais seria tão facilmente identificado como sobrevivente nem mesmo como um tipo de herói, reconhecido por sua ousadia e sua coragem, como nos séculos passados. Talvez por essa razão, a viagem de exploração se assemelhe a uma exibição de coragem, que se torna mais acentuada 
quanto mais for necessário compensar as dificuldades do narrador em se afirmar como testemunha. É como se o discurso do viajante-testemunha sofresse um reposicionamento, que, inclusive, repercute na questão da sua autenticidade:

[...] por mais honesto que seja o narrador, ele não pode, ele não pode mais, trazê-los sob uma forma autêntica. Para que consintamos em recebê-los, é preciso, por uma manipulação que entre os mais sinceros é apenas inconsciente, escolher e peneirar as recordações e substituir o vivido pelo convencional. (LÉVI-STRAUSS, 1996, p. 33).

"Ver o que poucos puderam ver", "pisar solo nunca antes pisado", a originalidade das narrativas deixa de constituir aspecto de suma importância, à medida que, "a todos, é permitido viajar". A função do viajante como mediador (talvez melhor definido como apresentador) foi sempre motivo de controvérsias ou reflexões, ao contrário do que o discurso um pouco nostálgico de Lévi-Strauss parece sugerir ${ }^{7}$. Seja como for, a necessidade de garantir a autenticidade do testemunho do viajante ganha caráter de encenação - "substituição do vivido pelo convencional" -, como pontua Lévi-Strauss (1996). O narrador-viajante é destituído de seu papel de observador privilegiado, mediador ocular, detentor de informações via experiência: sua posição perde exclusividade. Somos levados a compreender as reflexões de Tristes trópicos dentro de um momento de transição, em que a afirmação do viajante como testemunha parecia já soar como falsificação.

O público ao qual se refere Lévi-Strauss não parece ter, como motivação principal, a avaliação da autenticidade do testemunho, assim como também não parece interessado na contextualização mais ampla do que lhe fora apresentado. Mostra-se apenas atraído pela curiosidade e pela possibilidade de se deliciar com os efeitos estéticos que os testemunhos acabavam por proporcionar:

[...] nossos modernos Marco Polo trazem dessas mesmas terras, desta vez em forma de fotografias, de livros e de histórias, as especiarias morais que nossa sociedade experimenta uma necessidade mais aguda, sentindo-se sufocar pelo tédio? (LÉVI-STRAUSS, 1996, p. 33).

Sociedade entediada, que busca entretenimento. Público que se divertia e se emocionava há séculos com as histórias de aventura dos viajantes. Pensamos na função da literatura de viagem para amplo público-leitor, tão ou mais generalizado do que o público ao qual remete Lévi-Strauss - que pode ser compreendido como um público francês, mas também, mais amplamente, como europeu. Público majoritariamente europeu até os séculos XVII e XVIII e, gradualmente mais extenso, a partir da independência das antigas colônias e do próprio desenvolvimento da imprensa. Público progressivamente ampliado, conforme as literaturas nacionais também contassem com a literatura de viagem como referência. Se seguirmos essa ampliação, chegamos a uma

7. Dentre as estratégias de autenticidade dos relatos, pensamos na sofisticada estratégia utilizada por Michel de Montaigne (1999), em The cannibals: o envio de um serviçal ao novo mundo, tido como simples e honesto e, por essa razão, capaz de gerar um relato mais original. 
situação interessante: o público toma o lugar do narrador-viajante. Ambos se misturam; "todos" podem ser viajantes e, também, leitores e narradores.

A imagem do movimento acelerado indica alternância de papéis, em que as posições do narrador e do leitor não seriam mais marcadas pela contraposição entre mobilidade espacial e sedentarismo, uma vez que a condição de viajante e, por consequência, de enunciador foi tão ampliada quanto nunca antes havia ocorrido. Da mesma maneira, o texto e as ilustrações, que costumavam acompanhar os relatos, deixam de constituir o principal meio de expressão da experiência da viagem. A literatura de viagem é, portanto, redimensionada, o que acaba por alterá-la em relação à tradicional função de mediação entre viajante e público.

Contudo, não nos parece haver dúvidas sobre a existência de um forte elo entre a literatura e a amplificação das viagens; ligação, é claro, que não se desvincula de um conjunto de reestruturações e invenções tecnológicas: o avião, o automóvel, mas também o trem e o navio, cada vez mais funcionais e velozes. Poderíamos citar, ainda, o advento do telefone, do fax, da televisão, do vídeo, do computador e dos letreiros luminosos, além dos hotéis, das instâncias hidrominerais e de esqui, dos parques temáticos. E da câmera Kodak. Um conjunto de mudanças que permitiu não somente maior acesso às viagens de longa distância, mas também maior disseminação do imaginário sobre as viagens.

O imaginário das viagens, tanto tempo alimentado quase que exclusivamente pela literatura, conta com novas possibilidades de difusão e propagação de imagens e personagens. Hoje, as viagens são anunciadas como bens de consumo e comercializadas em pacotes "estampados" com imagens-clichê produzidas para estimular a contemplação fácil e o registro rápido durante itinerários padronizados. O caráter imagético do mercado das viagens produz não somente um número elevado de viajantes que circulam por destinos famosos, com o objetivo final de produzir as suas próprias imagens, também colabora para a superficialidade das experiências de viagem.

\section{O imaginário das viagens e a viagem-consumo}

As fotografias, livros e histórias de viagem que chegavam aos territórios europeus no século XX são interpretados por Lévi-Strauss, em Tristes trópicos, como um novo tipo de especiaria.

A Amazônia, o Tibé e a África invadem as lojas sob a forma de livros de viagem, relatórios de viagem e álbuns de fotografias em que a preocupação do efeito domina demais para que o leitor possa apreciar o valor do testemunho por eles trazido. Longe de despertar o seu espírito crítico, solicita ele cada vez mais desse alimento, e o engole em quantidades prodigiosas. (LÉVI-STRAUSS, 1996, p. 10).

A comparação de Lévi-Strauss nos parece bastante elucidativa, pois ressalta os testemunhos de viagem não somente sob o aspecto de sua produção, mas também sob o de sua recepção. Cores, odores, sabores acompanhavam materiais como a madeira, as 
tinturas, a pimenta e geravam efeito semelhante ao do testemunho: choque sinestésico, estranheza, curiosidade. Efeitos, por sua vez, alicerçados nos elementos do imaginário que marcaram as viagens, tais como o exótico, o maravilhoso, o fantástico e o grotesco.

É interessante pensar nos testemunhos da literatura de viagem como geração de efeitos que parecem fascinar ou mesmo expandir o público "faminto", ao qual se refere o autor. O narrador-viajante, por meio de sua descrição minuciosa (ou das suas fotografias cuidadosamente produzidas), articulava os elementos do imaginário na produção de seu testemunho ocular. Desde a época em que o narrador-viajante apresentava um tipo de condição espacial para a narração dos lugares, muito mudou, sendo interessante pensar as transformações nos meios de criação e difusão do imaginário.

Pensemos nas diferenças: as imagens produzidas pelos relatos do descobrimento e dos tempos que se seguiram, pelo fator ineditismo, doavam ao olhar do viajante um poder de mediação que se alargava quanto mais se expandia o mercado editorial à época. As técnicas de impressão, o desenvolvimento da fabricação do papel e o uso de tintas adequadas possibilitaram a impressão em massa também das histórias de viagem, que se tornaram, inclusive, um mercado lucrativo. Hoje, com o desenvolvimento acelerado dos meios de comunicação, as possibilidades foram multiplicadas. Texto, som e imagem conjugados e difundidos por aparelhos cada vez mais diversificados, portáteis e populares, sempre conectados em rede, expandem as possibilidades de atualização do imaginário das viagens. Ele se atualiza de modo muito mais difuso, conta com mais possibilidades de linguagem e resulta em conhecido efeito.

A sensação talvez seja a de que qualquer lugar do mundo está ao nosso alcance, basta que digitemos o nome do destino na tela do computador. Um sem número de imagens, todo tipo de fotografia e informações dispersas trazem a sensação de que o mundo é mais conhecido e está mais próximo de nós. Muitas vezes, não é preciso buscar aleatoriamente um destino de viagem, são exatamente os lugares que "chegam" até nós. Sistematicamente construída, a encenação midiática em torno das viagens seduz, produz desejos e incita o deslocamento. Alain de Botton, em seu relato de viagem $A$ arte de viajar, reflete sobre como foi seduzido por um folheto ilustrado com imagens de uma praia paradisíaca:

Sua capa mostrava uma fileira de palmeiras, muitas das quais crescendo inclinadas, na areia de uma praia orlada por um mar turquesa, tendo ao fundo montes onde imaginei cachoeiras e alívio do calor à sombra de árvores frutíferas de doce aroma. (BOTTON, 2003, p. 16).

Uma síntese do relaxamento, da fruição, o retrato de um modo de vida integrado à natureza. Por si só, a descrição da imagem já traz a familiaridade de uma composição que segue a mesma modulação de tantas outras que nos chegam cotidianamente. Trazem o poder de nos deslocar a um tempo remoto, de despertar em nós uma nostalgia de origem desconhecida ou mesmo de nos apresentar lugares tão diferentes, onde gostaríamos de estar, de viver. Tipo de imagem cujo poder advém também da matriz da qual deriva; matriz do exotismo, do maravilhoso e de um paraíso terrestre. São imagens às quais 
já nos acostumamos e que, com maior ou menor intensidade, desencadeiam um fluxo interno de memórias, de conexões entre imagens de várias naturezas:

As fotografias fizeram com que me lembrasse dos quadros do Taiti que William Hodges trouxera de volta de sua viagem com o Capitão Cook, que mostravam uma laguna tropical à delicada luz do entardecer onde sorridentes meninas nativas brincavam despreocupadas (e descalças) em meio à folhagem exuberante [...]. (BOTTON, 2003, p. 16).

Capitão Cook, assim como outros famosos viajantes, ajudou a construir um movimentado canal, por onde correm, desde então, imagens, pequenos textos e narrativas - fragmentos de várias culturas. Gerada no lastro de representações muito antigas, míticas e arraigadas em diferentes padrões culturais, essa faceta do imaginário sofreu um novo impulso com as representações ocidentais sobre o novo mundo ${ }^{8}$. São imagens e textos que compuseram um momento de renovação do imaginário ligado às viagens, marcando-o como um espaço ambíguo, no qual os encontros multiculturais acabavam dominados por uma abordagem ocidental. Nomeado como imaginário das viagens (AMIRON, 1995), nesse espaço acumulador de representações (GREENBLATT, 1996), são depositadas imagens sempre requisitadas a formar outras, como em uma cadeia híbrida em permanente construção. Certamente, esse conjunto de imagens nos alcança por meio do cinema documentário e de releituras das narrativas de viajantes famosos, pelas produções cinematográficas e animações e, claro, pelas imagens publicitárias.

É fácil constatar que reagimos de modo quase automático à simples descrição da imagem de uma praia paradisíaca, pois esse elemento nos é mais do que familiar. É como se, de alguma maneira, fôssemos atravessados por um conjunto simbólico-cultural relacionado às viagens, como se ele nos ocupasse um espaço interno que, dentre outros efeitos, nos permite reconhecer as representações do desconhecido ou do exótico como parte do que entendemos por viagem.

Os responsáveis pelo folheto tinham tido a sinistra intuição de como transformar os leitores em presas fáceis por meio de fotografias cujo poder insultava a inteligência e desrespeitava toda e qualquer noção de livre-arbítrio: fotos superexpostas de palmeiras, céus azuis e praias brancas. Leitores que teriam sido capazes de ceticismo e prudência em outras áreas da vida, em contato com esses elementos, revertiam a um otimismo e inocência primevos. Os anseios provocados pelo folheto eram um exemplo, ao mesmo tempo comovente e decepcionante, de como projetos (e até mesmo vidas inteiras) podem ser influenciados pelas imagens mais simples e incontroversas da felicidade; de como uma viagem prolongada e dispendiosíssima poderia ser posta em andamento por nada mais que a visão da fotografia de uma palmeira a se inclinar levemente com uma brisa tropical. (BOTTON, 2003, p. 16).

8. Outras imagens podem ser lembradas: as xilogravuras de Theodor de Bry nas Grandes viagens (coleção lançada em 13 volumes, no século XVI), a famosa Imagem do Novo Mundo, presente em Novus Mundus, de Américo Vespúcio, e as ilustrações de antropofagia de Duas Viagens ao Brasil, de Hans Staden. 
Uma imagem que provoca grandes anseios. Capaz de despertar a inocência e o otimismo de leitores geralmente céticos, prudentes e não menos enclausurados em suas vidas entediadas, amarrados ao trabalho, sufocados pelo cotidiano - "presas fáceis". Alain de Botton acaba por interpretar a atuação da publicidade das viagens como um jogo de sedução com base no imaginário, em que pessoas comuns desejam - ou precisam - ser seduzidas, sem que sejam necessariamente expostas ao risco de caminhar pelo desconhecido. Talvez não exatamente de sedução, a ideia da publicidade envolvida na venda de viagens seja a de um jogo de espelhos: a fotografia da ilha paradisíaca só adquire pleno sentido quando se abre para a projeção do leitor. Ele se imagina refletido no cenário tropical ou mesmo no lugar do fotógrafo, do observador: ele deseja a si mesmo no ambiente paradisíaco. A imagem não o interroga, não o intriga, apenas propõe que ele aceite ser projetado no cenário oferecido: eis o modo pelo qual o viajante começa a ser convertido em consumidor.

Associado à imagem paradisíaca, está o serviço de viagem: reservas nos hotéis, articulação do transporte e do seguro de viagem e, em muitos casos, programação a ser seguida no próprio destino. Conforto que parece nos oferecer algo, mas que também acaba por retirar de nós a própria necessidade de pensar em uma série de detalhes práticos (e importantes) e, por consequência, por reduzir o processo de fabulação da viagem. Quando o viajante aceita se tornar consumidor, o desejo da viagem nasce muito mais de "fora" do que de "dentro", e a viagem se assemelha a algo pronto, a um bem, a uma mercadoria ou mesmo, como tão bem resume a usual expressão, a um pacote. É justamente essa expressão que nos estimula a refletir sobre a relação entre viagem e consumo.

Ana Fani Alessandri Carlos (1999) ressalta o papel que os pacotes turísticos exercem na homogeneização do comportamento do viajante ao impor uma forma de usar o tempo e de se apropriar do espaço durante as viagens. Os pacotes turísticos, com rotas preestabelecidas e guias que elegem os lugares a serem visitados, induzem o turista a reconhecer as imagens pré-contatadas. A agência propõe o formato da viagem, e o consumidor, que pagou pelo pacote, exige constatar pessoalmente as imagens que foram anunciadas. $\mathrm{O}$ excesso e diversidade de informações e imagens veiculadas antes e durante as viagens provocam uma sobrecarga de locais a serem visitados, corroborada pelos pacotes turísticos, cujo lema é ver o máximo em menos tempo.

A rígida programação desses pacotes não dá espaço para o viajante entrar em contato com os lugares, pois seria necessário tempo para vivê-los, apropriar-se deles, descobrir seus significados e dotá-los de sentido. A insuficiência de tempo para permanecer nos lugares, com a obediência a uma programação prévia, torna o viajante um ser passivo, conduzido pelo guia de viagem (CARLOS, 1999).

Para o viajante-consumidor, o processo de constituição da experiência perde movimento. $\mathrm{O}$ ato de procurar, percorrer ou evadir tende a perder sentido para a constituição da experiência de viagem. Uma vez que não é mais fundamental nos movimentarmos para procurarmos um destino, perdemos não somente uma infinidade de possíveis direcionamentos, também e principalmente retraímos nossos percursos 
imaginativos, convertendo-os em uma linha reta que converge para um destino já enquadrado em imagens estereotipadas. Talvez por essa razão, as expectativas de viagem de Alain de Botton tenham se tornado tão estáticas:

\begin{abstract}
Nada era como eu imaginara - o que surpreende somente se pensarmos no que eu imaginara. Nas semanas precedentes, a ideia da ilha tinha girado exclusivamente em torno de três imagens mentais imóveis, colhidas durante a leitura de um folheto e de uma tabela de horários de vôos. A primeira era de uma praia com uma palmeira, tendo como fundo um pôr-do-sol. A segunda era de um chalé de hotel com portas envidraçadas que revelavam um quarto decorado com assoalho de madeira e roupa de cama branca. E a terceira era de um céu de puro azul. (BOTTON, 2003, p. 20).
\end{abstract}

Não podemos precisar as razões pelas quais as expectativas de viagem de Botton se resumiam a três imagens mentais imóveis. Suas impressões, no entanto, se encaminham não exatamente para uma reflexão sobre a natural decepção ou o reajuste que toda expectativa sofre tão logo a viagem tenha início. O que acaba se tornando central em seu relato é justamente a qualidade dessa expectativa: um tanto quanto ingênua, um tanto quanto infantil. Em busca de uma imagem simplificada da felicidade, a estada dele na ilha é mais marcada pela continuidade - de um estado de ânimos variados, alguma preocupação com o futuro, angústias, desentendimentos com sua companheira de viagem - do que por grandes transformações que lhe trouxessem a projetada felicidade. Não haveria, como constata Alain de Botton, maneira alguma de se tornar plenamente feliz - e alterar radicalmente algo em si - ao fazer da viagem uma simples troca de lugar.

\title{
Considerações Finais
}

Viajar e escrever, viajar e narrar. Viajar e ler, ler e viajar. A atividade de viajar parece intrinsecamente ligada à escrita e à leitura, como confirmam viajantes famosos que se inspiraram nos relatos de outros viajantes: Cristóvão Colombo - leitor de Marco Polo -, Lévi-Strauss - leitor de Jean de Léry - e, mais próximo de nosso tempo e do contexto brasileiro, Amyr Klink, viajante-escritor, leitor de Joshua Slocum. Como leitores, os viajantes buscam roteiros já traçados, lugares espiados e percorridos, mas, sobretudo, um conjunto de códigos de conduta, normas ou maneiras de melhor lidar com o tipo de experiência nomeado de viagem. Ao viajar, não somos os primeiros nem seremos os últimos a vivenciar determinadas situações. Por essa razão, as histórias que se tornaram clássicas e os viajantes que povoam nosso imaginário são tão importantes. E, dentro do universo da literatura de viagem - aparentemente restrito aos séculos passados e considerado, por muitos, como gênero substituído por um tipo de literatura mais sofisticada -, buscamos desenvolver a ideia do testemunho de viagem como mote capaz de provocar reflexões.

Dentre elas: os textos dos viajantes usualmente são lidos com um olhar suficientemente crítico, capaz de "burlar" a tendência a certa mitificação dos narradoresviajantes? Como buscar uma interpretação generosa dos textos dos mais variados 
viajantes, buscando submetê-los “(...) a uma crítica, com o objetivo de interpretar o conteúdo e o significado dessas imagens transmitidas” (LEITE, 1996, p. 22). Como abordar a literatura de viagem sem as restrições de um olhar preso ao caráter histórico dele, sem a pretensão de encontrar a gênese de categorias e conceitos das mais variadas disciplinas científicas, mas buscando compreendê-los como universo "vivo" e dinâmico? Afinal, quando se trata de literatura de viagem, é quase inevitável lidar com o dinâmico e pulsante imaginário, uma vez que ele é apropriado de modo tão intenso em nossos dias. Se o imaginário está vivo, as narrativas não deveriam ser traduzidas como textos estanques, mas como representação da experiência humana, tal como sugere Paul Ricoeur (1994) sobre todo e qualquer tipo de narrativa.

A proposta de reflexões não se encerra nesse ponto. Pelo contrário, a principal reflexão suscitada por meio do destaque ao testemunho de viagem, e a todos os aspectos envolvidos com a questão, diz respeito à necessidade de crítica ao mercado das viagens. $\mathrm{O}$ discurso sobre viagem parece pronunciar sempre a nós, potenciais consumidores, que é necessário viajar mais, sempre, para lugares distantes, servir-se de meios de transporte modernos, hospedar-se em hotéis. Há um superdimensionamento da viagem como modalidade de deslocamento espacial, sem que, em contraponto, seja proposta e explorada a promessa simbólica da viagem como busca de si próprio a partir do encontro com o outro. Nesse sentido, é importante a pergunta: o que nós, viajantes, desejamos alcançar por meio de uma viagem?

Desejamos relaxar, desfrutar o tempo de outra maneira que não a do cronômetro da rotina. Entregarmo-nos ao tempo, aos súbitos desejos, aos excessos, ao que não parece caber nos limites do cotidiano. Essas respostas, que soam tão usuais, fazem da viagem a representação da vida que não se pode viver, da vida que escorre lentamente pelos modos de vida modernos, centrados no trabalho, na luta pela sobrevivência, nas obrigações sociais. São desejos que, contraditoriamente, parecem estar muito mais centrados no próprio cotidiano do que no longínquo. Mas é fora do lugar da rotina que as possibilidades de outra vida ganham novas coordenadas, capazes de proporcionar o que os inóspitos ambientes urbanos, por exemplo, acabam por não oferecer. Se parece não mais haver tempo para criarmos nossos próprios itinerários de viagem, e percorrê-los lentamente, desejamos estar em outro lugar, para, assim, ganharmos a oportunidade de ser.

Viajar é a chance de estar em outro lugar. Ainda que o fascínio das viagens esteja diretamente relacionado a uma evasão planejada, que permite o afastamento de tudo aquilo que reprime, entendia e sufoca no familiar do cotidiano, as viagens parecem tolhidas em sua potencialidade de favorecer o encontro com o outro. A viagem contemporânea se assemelha a uma atividade em que as fronteiras do desconhecido são tateadas a distância, ainda que o viajante se desloque fisicamente. Um jogo de espelhos forjado pela publicidade, que, por sua vez, manipula imagens, convidando o sujeito a se projetar nos lugares. Para o viajante-consumidor, os lugares representam a projeção de suas frustrações e insatisfações cotidianas; obcecado por enxergar-se melhor onde quer que seja, ele faz com que o outro se torne um reflexo de sua própria imagem. 
Atração pelo desconhecido, medo, vulnerabilidade: todos esses fatores parecem muito distanciados da viagem contemporânea que é comercializada pelos agenciadores, operadoras, hoteleiros e guias. É importante pensar na transformação da viagem em uma atividade controlada, planejada e pretensamente isenta de riscos - sendo que os riscos aos quais nos referimos não dizem respeito unicamente à integridade física dos viajantes. A ausência de vulnerabilidade, disposição e exposição implicam, necessariamente, a redução das possibilidades de experimentação abrigadas pela ideia de viagem.

É de se pensar que há uma inibição sistematizada da experimentação associada à viagem, pelo menos pensada em sua versão autêntica, como atração pelo desconhecido. Um movimento interrompido, promessa que não se cumpre, encenação, superficialidade: princípio de um movimento de entrega que se desvia do outro para manter o viajante sempre em seu centro.

Assim, a viagem contemporânea é potencialidade latente, expressão de um desejo de abertura, encontro, transformações. Entretanto, por mais que seja a expressão de desejos daqueles que ousaram (e ousam) experimentar a si próprios a partir do outro, a viagem contemporânea ergue novos muros, recria bloqueios antigos, reforça as diferenças e fomenta um patriotismo exacerbado que serve ao preconceito, à intolerância, ao uso e abuso inconsequente e inconsciente dos destinos visitados. Há muito mais espaço, no mercado que explora as viagens, para se seguir orientado por um conjunto de normas e regras estabelecidas em critérios como a visibilidade, o excêntrico, o pitoresco do que para a criação de diálogos, ampliação da capacidade de compreender o outro, o reconhecimento do outro dentro de si.

\section{Referências Bibliográficas}

AMIRON, Rachid. Imaginaire touristique et sociabilites du Voyage. Paris: Presses Universitaires de France, c1995. 281p.

BOTTON, Alain de. A arte de viajar. Rio de Janeiro: Rocco, 2003. 253 p.

BARRETO, Margarita. Manual de iniciação ao estudo do turismo. 2. ed. Campinas: Papirus, 1995. $163 \mathrm{p}$.

BENNASSAR, Bartolomé. Dos mundos fechados à abertura do mundo. In: NOVAES, Adauto. (Org.) Brasil 500 anos, experiência e destino: a descoberta do homem e do mundo. Brasília: MEC/FUNARTE, 2000. p. 83-93.

BRAIT, Beth. Bakhtin, dialogismo e construção do sentido. Campinas, SP: Ed. da UNICAMP, 1997. 385 p.

CARLOS, Ana Fani Alessandri. O turismo e a produção do não-lugar. In: Turismo: espaço, paisagem e cultura. YAZIGI, Eduardo; CARLOS, Ana Fani Alessandri; CRUZ, Rita de Cassia Ariza da. (org.) 2. ed. São Paulo: Hucitec, 1999. p. 25-37.

CASTRO, Júlia Fonseca de; HISSA, Cássio Eduardo Viana. Uma leitura das viagens contemporâneas: a questão do testemunho nas narrativas de viagem. 2013. $159 \mathrm{f}$. 
Dissertação (mestrado em Geografia) - Instituto de Geociências, Universidade Federal de Minas Gerais, Belo Horizonte, 08 de abril de 2013.

CRISTOVÃO, Fernando. Condicionantes culturais da literatura de viagens: estudos e bibliografias. Lisboa: Cosmos: Centro Universidade de Lisboa, 1999. 437 p.

GREENBLATT, Stephen Jay. Possessões maravilhosas: o deslumbramento do novo mundo. São Paulo: Edusp, 1996. 200 p.

HISSA, Cássio E. Viana. A mobilidade das fronteiras: inserções da geografia na crise da modernidade. Belo Horizonte: Editora UFMG, 2006. 316 p.

KLINK, Amyr. Mar sem fim: 360 graus ao redor da Antártica. São Paulo: Companhia das Letras, 2000. 352 p.

LEITE, Ilka Boaventura. Antropologia da viagem: escravos e libertos em Minas Gerais no século XIX. Belo Horizonte: Editora UFMG, 1996. 269 p.

LEVI-STRAUSS, Claude. Tristes trópicos. Tradução de Rosa Freire de Aguiar. São Paulo: Companhia das Letras, 1996. 400 p.

MATOS, Mário Manuel Lima de; OPTIZ, Alfred. Postigos para o mundo: reflexões em torno do turismo e dos livros de viagem na RDA (1949-1989/90). 2007. Tese (Doutorado) - Universidade do Minho, Instituto de Letras e Ciências Humanas, Lisboa, 10 de abril de 2007.

MONTAIGNE, Michel de. Dos canibais. São Paulo: Alameda, 2009. 76 p.

PALHARES, Guilherme Lohmann; PANOSSO NETTO, Alexandre. Teoria do turismo: conceitos, modelos e sistemas. São Paulo: ALEPH, c2008. 486 p.

POLO, Marco. As viagens de Marco Polo. Adaptação de Carlos Heitor Cony e Lenira Alcure. Rio de Janeiro: Ediouro, 2005 [1254? - 1323?]. 118 p.

PRATT, Mary Louise. Os olhos do império: relatos de viagem e transculturação. Tradução de Jésio Hernani B. Gutierre Bauru: Edusc, 1999. 392 p.

RICOEUR, Paul. Tempo e narrativa. Campinas: Papirus, 1994. v. 1, 2 e 3.

SANTIAGO, Silviano. Nas malhas da letra: ensaios. São Paulo: Companhia das Letras, 1989. $235 \mathrm{p}$.

SELIGMANN-SILVA, Márcio. História, memória, literatura: o testemunho na era das catástrofes. Campinas: Editora da Unicamp, 2003. 555 p.

SLOCUM, Joshua; BRITO, Lucia. A viagem do Liberdade: do Brasil a Washington D.C. em uma canoa caseira com a esposa e dois filhos pequenos. São Paulo: Planeta, 2005. $155 \mathrm{p}$.

SONTAG, Susan. Sobre fotografia. Tradução de Rubens Figueiredo. São Paulo: Companhia das Letras, 2004. 223 p.

SUSSEKIND, Flora. O Brasil não é longe daqui: o narrador, a viagem. São Paulo: Companhia das Letras, 1990. 319 p. 
Júlia Fonseca de CASTRO

Doutoranda e mestre pelo Programa de Pós-Graduação em Geografia da Universidade Federal de Minas Gerais, na área de concentração Geografia Humana. Bacharel em Turismo pela Universidade Federal de Minas Gerais. Avenida Antônio Carlos, nº627. Pampulha. Belo Horizonte, Minas Gerais Juliafcastro@gmail.com

Recebido para publicação em dezembro de 2014 Aprovado para publicação em maio de 2015 